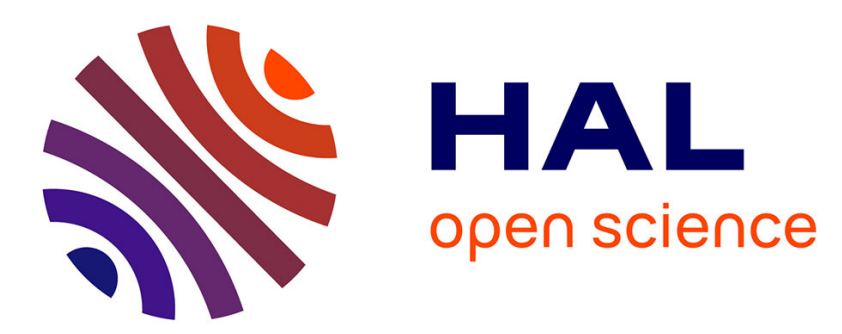

\title{
Impacts of intermittent sources on the quality of power supply: The key role of reliability indicators
}

Mathilde Drouineau, Nadia Maïzi, Vincent Mazauric

\section{To cite this version:}

Mathilde Drouineau, Nadia Maïzi, Vincent Mazauric. Impacts of intermittent sources on the quality of power supply: The key role of reliability indicators. Applied Energy, 2014, 116 (1), pp.333-343. 10.1016/j.apenergy.2013.11.069 . hal-00923577

\section{HAL Id: hal-00923577}

https://hal-mines-paristech.archives-ouvertes.fr/hal-00923577

Submitted on 15 Jan 2014

HAL is a multi-disciplinary open access archive for the deposit and dissemination of scientific research documents, whether they are published or not. The documents may come from teaching and research institutions in France or abroad, or from public or private research centers.
L'archive ouverte pluridisciplinaire HAL, est destinée au dépôt et à la diffusion de documents scientifiques de niveau recherche, publiés ou non, émanant des établissements d'enseignement et de recherche français ou étrangers, des laboratoires publics ou privés. 


\title{
Impacts of intermittent sources on the quality of power supply: The key role of reliability indicators
}

\author{
Mathilde Drouineau ${ }^{\mathrm{a}, *}$, Nadia Maïzi ${ }^{\mathrm{a}}$, Vincent Mazauric ${ }^{\mathrm{b}}$ \\ ${ }^{a}$ MINES ParisTech, Centre for Applied Mathematics, CS 10207, 06904 Sophia Antipolis \\ cedex, France \\ e-mails: mathilde.drouineau@yahoo.fr, nadia.maizi@mines-paristech.fr \\ ${ }^{b}$ Schneider Electric, Strategy $\&$ Innovation, 38TEC/T1, 37 quai Paul-Louis Merlin, \\ 38050 Grenoble, France \\ e-mail: vincent.mazauric@schneider-electric.com
}

\begin{abstract}
The reliability of power supply, defined as the ability to recover a steadystate condition after a sudden disturbance, is crucial for operating power systems. It is usually ensured by controlling voltage and frequency deviations and involves events occurring from a few milliseconds to a few hours. However, reliability requirements are largely ignored when dealing with longterm issues. To reconcile such contrasting timescales, it seems logical to rely on energy considerations based on thermodynamics. Two reliability indicators, assessing the magnetic and kinetic energy reserves of a power system, are derived from this approach. They enable to quantify the reliability of a given production mix and make it possible to choose between increasing shares of intermittent sources and maintaining an expected level of reliability. Since the indicators tackle reliability issues without focusing on a specific timescale, they are effective for both discussing the long-term evolution of reliability and improving the real-time management of a power system.
\end{abstract}

Keywords: Power system, Reliability of power supply, Intermittent sources, Thermodynamic variational principles

${ }^{*}$ Corresponding author is Mathilde Drouineau. 


\section{Introduction}

A reliable power supply is crucial for operating power systems. Defined as the ability of power systems to lock back into a steady-state condition after sudden disturbance (e.g. load or generation fluctuations), reliability is usually ensured through appropriate management of voltage and frequency and involves events whose time scales range from a few milliseconds to a few hours. However, when focusing on power systems long-term development (typically several decades), reliability requirements are largely ignored thus providing unrealistic options in this area. Yet this aspect is of tremendous importance, especially when high shares of renewable energy sources, and in particular intermittent energy sources, are expected in electricity generation and may threaten supply reliability.

The International Energy Agency anticipates a major growth in electricity consumption over the coming decades, as a result of the predicted population densification, the development of energy markets in developing countries, and the replacement of existing capacities in developed countries, while several issues, such as the mitigation of greenhouses gases, call for new ways of producing electricity to increase the shares of cleaner and inexhaustible energy sources [1]. In this context, the emergence of different paradigms for serving electricity than those for which the system was designed [2] challenges the forthcoming changes in power systems. In particular, high shares of renewable energy sources may become a critical aspect of future energy systems, both for centralized scheme and for distributed architecture. The integration of renewable energy sources in electricity production has indeed been widely studied to determine their development's challenges and options. $[3,4,5,6]$. Different energy system analyses of $100 \%$ renewable energy systems were conducted for different areas $[7,8,9]$ and tools are developed to model future energy systems with high penetration of renewable energy sources $[10,11]$. The previous analyses rise several technical challenges posed by the largescale integration of renewables, mainly wind power and photovoltaics, that are listed in $[12,13]$. They point out that accurate short-term forecasts of power output (over the next few hours or days) are important factors for a secure and economic operation of power systems. Besides, to increase the variable power integration in the generation mix and consequently increase their share of renewables, it is possible to take advantage of the electricity systems' flexibility which exists on both the production side [14, 15] and the consumption side $[16,17]$. 
This power generation evolution brings the quality of power supply into question. High shares of intermittent sources expected may indeed threaten the reliability of future power systems, where reliability is intended as the ability of the power system to lock back into steady-state conditions after power imbalances. So far, power systems' reliability requirements in the longterm have been investigated through cost and market prices' issues [18, 19, 20].

In this paper, we propose to assess reliability of power supply. Indeed it is necessary to provide plausible energy strategy in the electricity sector especially when including high shares of intermittent production. As defined in the ENTSO-E handbook [21], reliability corresponds to the adequacy and security of power supply, which describe its ability to respectively comply with electrical demand at all times and withstand the system's contingencies such as unanticipated loss of a system element. So far, system operators have addressed the different aspects of reliability of supply by employing various methods that we have divided into:

- short time scales methods (assessing reliability from a few milliseconds to a weekly or monthly basis);

- long-term methods (assessing reliability from one to twenty years).

Short time scales methods include real-time controls and optimal power flow (OPF) studies. During daily operations, real-time frequency and voltage controls manage the active and reactive power outputs of generators to prevent frequency and voltage deviations in the system. Primary, secondary and tertiary reserves of active or reactive power are respectively activated for frequency or voltage management at different time steps varying from a few milliseconds to a few minutes [21]. Beyond the real-time management, $\mathrm{OPF}$ are typically used for scheduling daily or weekly production plans while maintaining a reliable power supply thanks to a set of constraints including transmission line limits and other security limits or margins [22, 23, 24]. The OPF aim to minimize the operating cost of the power system subject to satisfying power flow constraints and constraints on generator power, line power flow or voltage magnitude.

Long-term methods refer to methods assessing reliability of supply over several years. For five years or so, power supply reliability is assessed in terms of whether generation matches the expected demand [25, 26, 27]. Due to the random nature of parameters involved in the calculations (unit availability, 
weather conditions), the match between supply and demand is assessed using common statistical measures: Loss of Load Probability (LOLP), Loss of Load Expectation (LOLE) and Expected Unserved Energy (EUE). LOLP and LOLE measure respectively how long and how frequently, on average per year, the available capacity is likely to fall short of demand, while EUE evaluates the corresponding unsatisfied demand. LOLP and LOLE are also used in PV sizing methodologies to get the most probable insight of the power output the system may deliver during a day and also the next days in a short term approach for power prediction. Beyond a decade, planning exercises, such as generation expansion planning models, determine the generation units to be constructed, the timing of investments, and the amount of power to be produced, while minimizing the total cost of a utility over ten to twenty years. Such exercises only focus solely on adequacy issues regarding reliability of supply and reliability is ensured through constraints on LOLP or on the levels of active and reactive power reserves [28]. Similarly, reliability is only assessed with statistical measures in transmission expansion planning exercises [29].

However, both short time scales methods and long-term methods are insufficient to analyze in a long-term perspective the ability of the power system to lock back into steady-state conditions after power imbalances. On the one hand, short terms actually give insights to power systems dynamics and stability but cannot be processed with long-term studies for guiding energy strategies. On the other hand, the statistical measures used in the mid- to long-term methods do not give any indications as to the dynamical properties of the generation mix, and subsequently do not fully assess the system's ability to withstand sudden disturbances.

Since reliability requirements and the long-term development of power systems involve significantly different timescales, it is therefore appealing to rely on energy considerations in order to reconcile the timescales. Given that energy conservation results from the uniformity of time [30], we develop herein an approach that assesses the reliability of supply by evaluating the evolution of the energy reserves stored in a power system. Therefore, the thermodynamic framework, which is a natural framework to study energy exchanges, provides an original way to quantify the reliability of power supply for a production mix, whatever the timescale studied (i.e. long and short timescales).

The method proposed in this paper is rooted in energy-based analysis. The method however differs from energy-based methods derived from [31, 32] 
and used to study power system transient stability that aim at estimate whether or not a power system will remain in synchronism after a large disturbance. Inversely, the approach presented in this paper can be used to discuss both in short- and long-term perspectives the conditions enabling to ensure a minima reliability of supply (as described aforementioned). Yet, this is of critical importance to determine plausible shares of intermittent sources in electricity production.

Section 2 presents the theoretical developments based on a variational formulation on which the proposed methodology relies. It exhibits the energy reserves stored in a power system during power transactions and highlights their role in efficiently managing transient states. Section 3 introduces two reliability indicators that are deduced from a quantitative evaluation of the energy reserves. The indicators provide valuable insights for debating the reliability of power systems' management according to their dynamical properties. Lastly, the relevance of the indicators is demonstrated in the fourth section through reliability analyses that study both the long-term evolution and the real-time management of supply reliability in the remote power system on Reunion Island.

\section{Applying a Variational Formulation to Power Systems' Analysis}

This section describes the dynamics of a power system relying on energy considerations based on thermodynamics. We present a variational formulation of electromagnetism that provides an understanding of power transactions including an explanation of transient regimes with the variations of the magnetic and kinetic energy reserves stored in the system.

\subsection{Variational Principles in Electromagnetism}

As a general rule in this paper, italic fonts will denote variational parameters or functionals, and roman fonts their minimum value.

Relying on thermodynamics enables to focus on power conversions to determine the evolution of a complex system, and avoids an exhaustive description of the components of an electromagnetic system (e.g. network architecture). Thermodynamics assume that steady-state conditions are obtained from the maximum-entropy principle and comply with its macroscopic information, namely the internal energy $E$, and, in the specific case of an electromagnetic system, the magnetic flux $\Phi$ and the electric charge $Q$ squeezed from the earth. Nevertheless, thermodynamic approaches of electromagnetism do 


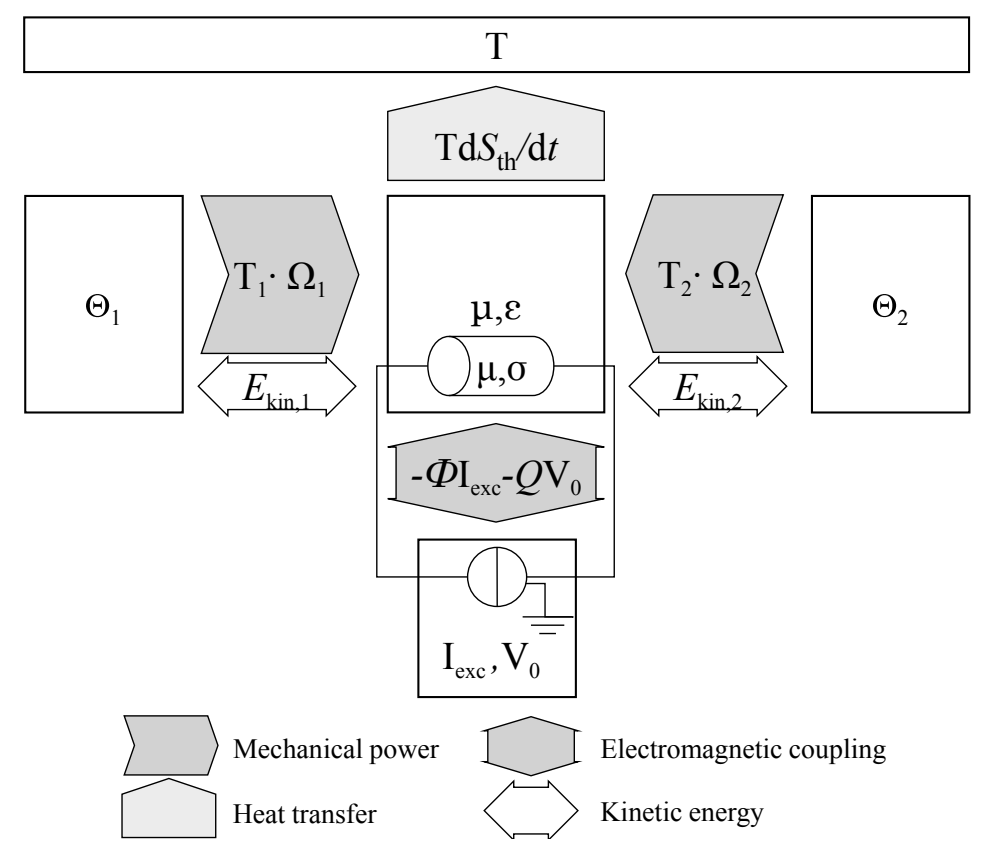

Figure 1: Chart of the energy exchanges between the subsystems involved in the thermodynamic representation of a power system [33,34]. $(\mu, \epsilon)$ and $(\mu, \sigma)$ respectively described conductors and dielectrics immersed in the electromagnetic field conveying power between the subsystems. Arrows illustrate the power exchanges.

not usually describe time-varying regimes [35], and no general contribution exists for transient regimes despite the improvements for steady-state regimes summarized in [36]. However, a variational approach of electromagnetism can be derived from thermodynamic principles and provide an explanation for non steady-state conditions [33].

As depicted in figure 1, the electrical machines $\Theta_{i}$ exchange mechanical power $\mathrm{P}_{\text {mech-ext }}=\sum_{i} \mathbf{T}_{i} \cdot \Omega_{i}$ through the electrical network, where:

- $\Omega_{i}=\mathrm{d} \Theta_{i} / \mathrm{d} t$ is the angular velocity of the machine experiencing the external torque $\mathbf{T}_{i}$;

- $\left(\Phi \mathrm{I}_{\text {exc }}+Q \mathrm{~V}_{0}\right)$ represents the coupling energy between the electromagnetic field and its sources (mass at voltage $\mathrm{V}_{0}$, current excitation $\mathrm{I}_{\text {exc }}$ );

- all subsystems exchange heat with the thermostat at the temperature $\mathrm{T}$ and electrical charges with the mass at the potential $\mathrm{V}_{0}$. 
Basically the excitation $\mathrm{I}_{\text {exc }}$ and $\mathrm{P}_{\text {mech-ext }}$ can be adjusted directly by the system operator. The first principle of thermodynamics conveys the energy conservation:

$$
\frac{\mathrm{d} E}{\mathrm{~d} t}=P_{\text {mech-int }}-\mathrm{T} \frac{\mathrm{d} S_{\mathrm{th}}}{\mathrm{d} t}
$$

where:

- $P_{\text {mech-int }}$ denotes the electrodynamical power supplied to the electromagnetic field which differs from the mechanical power $\mathrm{P}_{\text {mech-ext }}$ supplied to the system because of the variations of the kinetic energy $E_{\text {kin }}$ :

$$
\mathrm{P}_{\text {mech-ext }}-P_{\text {mech-int }}=\frac{\mathrm{d} E_{\text {kin }}}{\mathrm{d} t}
$$

- $S_{\text {th }}$ is the entropy of the thermostat at the temperature T.

The evolution of the system coupled with the thermostat can be discussed from its Helmoltz free-energy $F=E-\mathrm{T} S$ :

$$
P_{\text {mech-int }}-\frac{\mathrm{d} F}{\mathrm{~d} t}=\mathrm{T}\left(\frac{\mathrm{d} S}{\mathrm{~d} t}+\frac{\mathrm{d} S_{\mathrm{th}}}{\mathrm{d} t}\right)=P_{\text {Joule }}>0
$$

where $S$ describes the entropy of the system. The RHS represents the power lowered in heat, known as the Joule losses $P_{\text {Joule }}$ which are always positive according to the second principle. Thereby, the most reversible evolution of the system is ensured when lowering the Joule losses:

$$
\mathrm{P}_{\text {mech-int }}-\frac{\mathrm{dF}}{\mathrm{d} t}=\min \left(P_{\text {Joule }}\right)
$$

However, to fully describe the inertial behavior of the electromagnetic coupling (i.e. Lenz's Law), we must introduce the Gibbs free-energy $G=$ $F-\Phi \mathrm{I}_{\text {exc }}-Q \mathrm{~V}_{0}$ thus expressing another reversible assignment:

$$
\mathrm{P}_{\text {mech-int }}-\frac{\mathrm{d} \mathrm{G}}{\mathrm{d} t}=\min \left(P_{\text {Joule }}+\frac{\mathrm{d} \Phi \mathrm{I}_{\text {exc }}}{\mathrm{d} t}+\frac{\mathrm{d} Q \mathrm{~V}_{0}}{\mathrm{~d} t}\right)
$$

In (5), the RHS of the functional exhibits $\Phi$ and $Q$ which are the derivatives of the Gibbs free-energy $G$ :

$$
\Phi=-\frac{\partial G}{\partial \mathrm{I}_{\mathrm{exc}}} \quad ; \quad Q=-\frac{\partial G}{\partial \mathrm{V}_{0}} \quad ; \quad S=-\frac{\partial G}{\partial \mathrm{T}}
$$


Hence, the functional in (5) balances the variations with time of the Gibbs free-energy $\mathrm{G}$ and the electrodynamical power supplied to the field. The reversibility tendency expressed in (5) provides the Maxwell-Faraday's equation in conductors [33], which can be understood as the local expression of a global tendency towards reversibility [37,38]. Such findings give a thermodynamic insight into the variational theory of electromagnetism [39].

\subsection{Magnetic and kinetic reserves stored in a power system}

The above approach provides an understanding of power transactions that can be applied at different length scales, e.g. from materials involved in electrical engineering to apparatus design and grid management [40, 41, 42]. To describe a given subsystem $\mathcal{V}$, it is convenient to introduce the electrical power $\mathrm{P}_{\text {elec }}(\mathcal{V})$ which measures the local deviation of $\mathcal{V}$ from the equilibrium. Of course, the global power balance of the system provides:

$$
\sum_{\cup \mathcal{V}} \mathrm{P}_{\text {elec }}(\mathcal{V})=0
$$

After some calculations described in [33], $\mathrm{P}_{\text {elec }}(\mathcal{V})$ matches the integral form of the Poynting's conservation equation:

$$
\mathrm{P}_{\text {elec }}(\mathcal{V})=\mathrm{P}_{\text {Joule }}(\mathcal{V})+\frac{\mathrm{dF}}{\mathrm{d} t}(\mathcal{V})-\mathrm{P}_{\text {mech-int }}(\mathcal{V})
$$

where $\mathrm{F}(\mathcal{V})$ matches the electromagnetic energy of the field limited to $\mathcal{V}$ at the thermodynamic equilibrium. Substituting (2) into (8), the Poynting's equation checks:

$$
\mathrm{P}_{\text {mech-ext }}(\mathcal{V})+\mathrm{P}_{\text {elec }}(\mathcal{V})=\mathrm{P}_{\text {Joule }}(\mathcal{V})+\frac{\mathrm{dF}}{\mathrm{d} t}(\mathcal{V})+\frac{\mathrm{dE}_{\text {kin }}}{\mathrm{d} t}(\mathcal{V})
$$

For steady-states, Poynting's equation (9) describes regimes for which the mechanical power received by (or supplied to) $\mathcal{V}$ is balanced by the electrical supplied to (or respectively received by) the rest of the system to which is added the power dissipated in Joule losses. In general, Poynting's equation includes an explanation of transient regimes thanks to the energy reserves in $\mathcal{V}$, namely $\mathrm{F}$ and $\mathrm{E}_{\text {kin }}$. According to this approach, a power system after a contingency (e.g. production or load fluctuation, network contingency) relies on the variations of its electromagnetic coupling energy $\mathrm{F}$ and of its kinetic reserve $E_{\text {kin }}$. The stored energy in the form of electromagnetic and kinetic 
reserves both enable a rapid adjustment of power exchanges and provide inertia to the system until the production plan is realigned. In addition, if $\mathrm{F}$ vanishes, the reversibility condition (5) no longer complies with MaxwellFaraday's Law, thus highlighting the critical role of the electromagnetic reserve to locally operate the electrical machines and to ensure the overall power transmission.

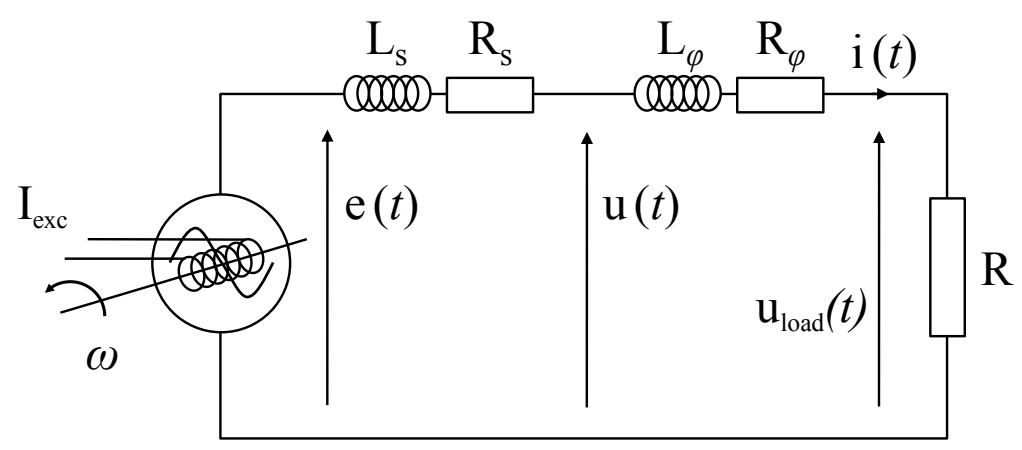

Figure 2: Single-phase representation of the one-loop circuit.

A qualitative analysis, based on the simple one-loop circuit depicted in figure 2, aims at determining the magnitudes of both the reserves and their relaxation time constants. The dynamical properties of production, transmission and consumption equipments are described as follows:

- $\mathcal{V}_{\text {prod }}$ simulates the behavior of a three-phase ac synchronous generator, where $\mathrm{e}(t)$ is the open-circuit voltage and $\mathrm{u}(t)$ the terminal voltage. The variations of the angular velocity and the electrical pulsation are denoted by $\Omega(t)$ and $\omega(t)$. The stator is described by its inductance $\mathrm{L}_{s}$ and resistance $\mathrm{R}_{s}$, and the rotor by its angular velocity, proportional to the angular frequency $\omega$ and its excitation current $\mathrm{I}_{\mathrm{exc}}$;

- $\mathcal{V}_{\mathrm{T} \& \mathrm{D}}$ gathers the inductive $\mathrm{L}_{\varphi}$ and resistive $\mathrm{R}_{\varphi}$ properties of the transmission and distribution equipment, causing the voltage to drop to $\mathrm{u}_{\text {load }}(t)$;

- $\mathcal{V}_{\text {load }}$ accounts for the behavior of all consumers, which is depicted as a single resistance $\mathrm{R}$ in a first approximation. This paper thereby focuses on the magnetic and kinetic inertia provided by the production side and the transport and distribution equipment. 
- Variations of $Q \mathrm{~V}_{0}$ are neglected since the magnetic energy stored in electrical machines is $10^{4}$ higher than the electrostatic energy [43]. The magnetic energy is produced and kept within the magnetically coupled coil windings.

During transient states, power transactions can be described as two subproblems whose relaxation time constants differ by three orders of magnitude. Assuming that the two problems can be dealt with separately, it is possible to verify that the problems occur at different timescales.

Firstly, a rapid electrical problem works out the variations in voltages and currents in the phase armature windings and consequently also describes the dynamics of the magnetic energy $F$, which depends on the voltage and current variations. An explicit reference to time variations, denoted by $(t)$, describes the functions during transient states.

$$
\mathrm{e}(t)=\left(\mathrm{R}_{s}+\mathrm{R}_{\varphi}+\mathrm{R}\right) \mathrm{i}(t)+\left(\mathrm{L}_{s}+\mathrm{L}_{\varphi}\right) \frac{\mathrm{di}(t)}{\mathrm{d} t}
$$

where the relaxation time constant reads:

$$
\tau_{\text {elec }}=\frac{\mathrm{L}_{s}+\mathrm{L}_{\varphi}}{\mathrm{R}_{s}+\mathrm{R}_{\varphi}+\mathrm{R}}
$$

$\tau_{\text {elec }}$ evaluates the time for the system to adapt to a change in voltage or current and thus the dynamics of F.

Secondly, a slower mechanical problem describes the energy conservation and rules the variations of $\omega(t)$ and $\mathrm{E}_{\mathrm{kin}}(t)$ according to the Poynting's equation (9) and assuming that $\mathrm{dF} / \mathrm{d} t=0$ since its variations are ruled with the previous electrical problem :

$$
\mathrm{J} \omega(t) \frac{\mathrm{d} \omega(t)}{\mathrm{d} t}=\mathrm{P}_{\text {mech-ext }}(t)+\mathrm{P}_{\text {elec }}(t)-\mathrm{P}_{\text {Joule }}(t)
$$

For small variations of $\omega(t),(12)$ is linearized around the rated value $\omega_{0}$ which shows the mechanical relaxation time constant:

$$
\tau_{\text {mech }} \approx \frac{\mathrm{J} \omega_{0}^{2}}{\mathrm{P}_{\text {mech-ext }}}
$$

Numerical applications based on table 2 show that the constants satisfy $[44,34]$ :

$$
\tau_{\text {elec }}<\frac{2 \pi}{\omega_{0}} \ll \tau_{\text {mech }}
$$


$\tau_{\text {elec }}$ varies by a few milliseconds and $\tau_{\text {mech }}$ by a few seconds. The inequalities in (14) confirm that the two problems are ruled by different dynamics. Since $\tau_{\text {elec }}$ is smaller than an electrical period, steady-state conditions are recovered within a period. Such results shows that voltages and currents adapt almost instantly to a disturbance and enables to ignore electrical transients in our problem. Inversely, $\omega(t)$ varies slowly compared to an electrical period, causing the system to evolve in pseudo steady-state conditions for which a frequency deviation occurs while voltages and currents experience steady-state conditions.

In steady-state and pseudo steady-state regimes, it is convenient to rely on the complex expressions of the sinusoidal functions, i.e. the phasor representation, to describe voltages and currents. An explicit formulation of the total magnetic energy $\mathrm{F}$, i.e. the sum of self of mutual inductances, can then be provided based on a phasor representation:

$$
\mathrm{F}=\frac{1}{2} \mathrm{~L}_{r}\left|\underline{\mathrm{I}}_{\text {exc }}\right|^{2}\left(1-\frac{3 \mathrm{M}^{2}}{\mathrm{~L}_{r}\left(\mathrm{~L}_{s}+\mathrm{L}_{\varphi}\right)} \sin ^{2} \psi\right)
$$

where $\mathrm{L}_{r}$ is the rotor self and mutual inductances, |.| denotes the absolute value of a complex number, $\mathrm{M}$ is the value of the stator-rotor mutual inductances, and $\psi$ the phase difference between the open-circuit voltage and the current (see Appendix A for more details).

Only the production side $\mathcal{V}_{\text {prod }}$ contributes to the kinetic reserve in the one-loop circuit. Using basic mechanics, it comes out as:

$$
\mathrm{E}_{\mathrm{kin}}=\mathrm{E}_{\mathrm{kin}}\left(\mathcal{V}_{\text {Prod }}\right)=\frac{1}{2} \mathrm{~J}^{2}=\frac{1}{2} \mathrm{~J}(\omega / \mathrm{p})^{2}=\mathrm{HS}_{n}
$$

where $\mathrm{p}$ is the number of pairs of poles, $\mathrm{J}$ the inertia moment of the coupled turbine and generator rotor, $\mathrm{S}_{n}$ the apparent power of the generator, and $\mathrm{H}$ the per-unit inertia constant, measured in seconds, typically ranging between 1 and 10 seconds $[22,45]$.

\section{Reliability Indicators and Power System Management}

The previous developments provide a description of power systems dynamics that overcomes the standard time-harmonic description and gives valuable indications as to the ability of power systems to respond to sudden disturbances. A load fluctuation can indeed be efficiently managed if adjustments of the electromagnetic energy $\mathrm{F}$ and the kinetic reserve $\mathrm{E}_{\text {kin }}$ last until 
the production level can be realigned, while inversely a short circuit can lower all the electromagnetic energy, thus leading to a possible loss of synchronism between the generators and a subsequent collapse of power transmission.

We now define two reliability indicators $\mathrm{H}_{\text {mag }}$ and $\mathrm{H}_{\text {kin }}$ that evaluate respectively the levels of magnetic or kinetic energy stored in a power system. To the best of our knowledge, the reliability indicators propose the first comprehensive approach suitable for long-term planning exercises that describes the dynamics of a given power system, depending on the characteristics of its power units. The indicators are defined thanks to the explicit formulations of the magnetic and kinetic reserves introduced in (15) and (16) respectively. They have the dimension of time ${ }^{1}$ ( $\mathrm{ms}$ or $\mathrm{s}$ ) and are expressed in terms of per-unit parameters:

$$
\begin{aligned}
\mathrm{H}_{\text {mag }} & =\frac{\mathrm{F}}{\sum_{k} \mathrm{~S}_{n, k}} \\
\mathrm{H}_{\text {kin }} & =\frac{\mathrm{E}_{\mathrm{kin}}}{\sum_{k} \mathrm{~S}_{n, k}}
\end{aligned}
$$

where the sum is achieved over all the machines delivering power to the system $^{2}$. The indicators quantify the time it takes for each reserve to become exhausted if all production is suddenly disconnected. Interestingly, other values representing the reserves could be used to build alternative indicators according to the user: the rated power of the machines expressed in the numerators of (17) and (18) may for instance be replaced with the power they supply.

Typical values vary from a few milliseconds for $\mathrm{H}_{\text {mag }}$, to a few seconds for $\mathrm{H}_{\text {kin }}$. The difference in magnitude of $\mathrm{H}_{\text {mag }}$ and $\mathrm{H}_{\text {kin }}$ is closely linked to the difference in magnitude of $\tau_{\text {elec }}$ and $\tau_{\text {mech }}$. It illustrates the sequence of use of the reserves and their distinct functions in the voltage and frequency primary controls:

- adjustments for the magnetic reserve $\mathrm{F}$ occur in a few milliseconds: the magnetic energy is utilized shortly after a fluctuation (few ms) and

\footnotetext{
${ }^{1}$ The indicators are expressed in $\mathrm{J} / \mathrm{kVA}$ thus having the dimension of time.

${ }^{2}$ As defined, $\mathrm{H}_{\text {kin }}$ equals $\mathrm{H}$ for a single generator.
} 
plays a crucial role in preventing from power transmission failures, thus ensuring that pseudo steady-state conditions can be recovered within a small number of periods;

- changes in $\mathrm{E}_{\text {kin }}$ happen in a few seconds: the kinetic energy compensates for unbalanced power transactions over a longer period (few s);

before any action can be taken to adjust $\mathrm{P}_{\text {mech-ext }}(t)$ and $\mathrm{I}_{\text {exc }}(t)$.

Next, voltage regulators and speed governors have respectively appropriate actions on the excitation current $\mathrm{I}_{\text {exc }}$, and $\mathrm{P}_{\text {mech-ext }}$ (e.g. through the inlet valve of the turbine). Voltage and frequency are then automatically restored to their set-points within secondary controls. Finally, the production plan is manually adjusted to reconstitute the reserves within tertiary controls $[21,46,22]$. This sequence of actions ensures a reliable management of the system.

The reliability indicators are useful to quantify the magnetic and kinetic reserves in a power system. The levels of the reserves have direct impacts on the voltage and frequency drops that a power system must withstand: the greater the indicators, the more reliable is the power system.

To challenge the different timescales exhibited above, we remind the time frames for the provision of ancillary services related to frequency and voltage controls [47, 48]. Frequency controls are services related to the short-term balance of energy of the power system. The primary frequency regulation service fixes the imbalances in real time: it consists of the provision of a suitable generation capacity of autonomous response, by means of extra generation capacity, to keep the frequency inside its nominal value. The primary regulation is a global setting, based on the primary reserves of all the generation units connected to the grid. Then, operational reserves are intended to save the system from a major failure and correspond to short-term available generation used to manage the imbalance between energy supply and energy demand. The secondary frequency regulation sets frequency back to its nominal value, offsets the power imbalances between the different power system's areas and reconstructs the primary reserves with a response period between approximately $10 \mathrm{~s}$ and $15 \mathrm{~min}$. Finally, two other types of operational reserves can be distinguished: tertiary frequency regulation, that must be available within the range of $10-30 \mathrm{~min}$, and non-synchronized reserves units, that neither have been dispatched not even connected to the grid, but that can be connected and ready to start generating within a period 
of about $30 \mathrm{~min}$. Concerning voltage control consists of the use of generation and transmission resources needed to keep the voltage within the range required by the system. This service consists of the production and availability of reactive power injection to solve the problems of low-voltages busbars, and with the capability to absorb reactive power for high-voltage busbars. In both ways there is a dynamic service delivered in a continuous time frame to face busbar voltage changes.

Then, we illustrate the role the indicators can play by analyzing a power system's response to load fluctuation for different values of $\mathrm{H}_{\text {mag }}$ and $\mathrm{H}_{\mathrm{kin}}$ as depicted in figure 3. In the figure, frequency and terminal voltage deviations are studied during transient regimes, namely after a significant load fluctuation, for systems with different rated power. Following the assumptions made in the previous section, a load fluctuation is modeled by suddenly increasing the consumption $\mathrm{P}_{\text {elec }}(t)$ of a certain amount $\Delta \mathrm{P}$, i.e. by decreasing $\mathrm{R}$ as described in power system analysis by the (P-V) curves [22]. Additionally, $\mathrm{P}_{\text {mech-ext }}$ and $\left|\underline{\mathrm{I}}_{\text {exc }}\right|$ are set independent of time, thus illustrating the role of the reserves before the production plan can be realigned. The analysis is conducted on an isolated power system in which power production can vary between 200 and $1000 \mathrm{MW}$, which corresponds to the case of a small island. A load fluctuation of $52 \mathrm{MW}$ is simulated, i.e. losing approximately $5 \%$ of the rated power, which is likely on an island (this calibration was made for Reunion Island and is further analyzed in the next section). Tables 1 and 2 present the parameters used in the study and the electrical values before the fluctuation. Figures 3(a) and 3(b) present results of the simulation and respectively show the voltage and frequency deviations after the fluctuation.

Figure 3(a) depicts $\left|\mathrm{U}_{0}^{+}\right|$, the generator terminal voltage after a small number of periods following the fluctuation, i.e. right after the fluctuation since the electrical transient is neglected. At this stage, steady-state conditions are recovered thanks to the magnetic reserve, while in contrast $\omega(t)$ and the kinetic energy have not yet fluctuated. Different simulations are performed for values of $\mathrm{H}_{\text {mag }}$ ranging between 3 and $25 \mathrm{~ms}$. This figure illustrates that the greater the magnetic reserve in the system, the smaller the deviation of $|\underline{\mathrm{U}}|$. Indeed, further calculations demonstrate that higher levels of magnetic energy correspond to lower values of $\mathrm{L}_{s}[49,34]$, thus explaining the weaker effect of $\Delta \mathrm{P}$ on the voltage drop.

Figure $3(\mathrm{~b})$ represents $f_{10}$, the frequency 10 seconds after the fluctuation. At this timescale, the kinetic energy strongly compensates for the power imbalance, whereas the magnetic energy scarcely does, since voltages and 


\begin{tabular}{|c|c|c|c|}
\hline Parameters & Constants & $f\left(\mathrm{P}, \mathrm{H}_{\mathrm{mag}}, \mathrm{H}_{\mathrm{kin}}\right)^{a}$ & Rated value \\
\hline \multicolumn{4}{|l|}{ Production } \\
\hline $\mathrm{P}_{\text {mech-ext }}(\mathrm{MW})$ & & $\in[200 ; 1000]$ & 1000 \\
\hline $\mathrm{H}_{\mathrm{mag}}(\mathrm{ms})$ & & $\in[3 ; 25]$ & 3 \\
\hline $\mathrm{H}_{\mathrm{kin}}(\mathrm{s})$ & & $\in[3 ; 25]$ & 3 \\
\hline$\omega_{0}\left(\operatorname{rad} . \mathrm{s}^{-1}\right)$ & 314 & & \\
\hline $\mathrm{p}$ & 1 & & \\
\hline $\begin{array}{l}J\left(\mathrm{~kg} \cdot \mathrm{m}^{2}\right) \\
\cos \varphi\end{array}$ & 0.85 & $2\left(\mathrm{H}_{\mathrm{kin}}\right) \mathrm{S}_{n} / \omega_{0}^{2}$ & $711 \mathrm{e}^{3}$ \\
\hline $\mathrm{S}_{n}(\mathrm{MVA})$ & & $\mathrm{P} / \cos \varphi$ & 1176 \\
\hline $\mathrm{U}_{n}(\mathrm{kV})$ & 63 & & \\
\hline $\mathrm{Z}_{n}(\Omega)$ & & $\left(\mathrm{U}_{n}^{2} / 3\right) / \mathrm{S}_{n}$ & 1.124 \\
\hline $\mathrm{x}_{s}$ (p.u.) & & $f\left(\mathrm{H}_{\mathrm{mag}}\right)$ & 1.97 \\
\hline $\mathrm{r}_{s}$ (p.u.) & & $0.005 \mathrm{x}_{s}$ & 0.0098 \\
\hline$\underline{\mathrm{Z}}_{s}(\Omega)$ & & $\mathrm{Z}_{n}\left(\mathrm{r}_{s}+j \mathrm{x}_{s}\right)$ & cf. below \\
\hline$\overline{\mathrm{R}}_{s}(\Omega)$ & & $\operatorname{Re}\left(\underline{Z}_{s}\right)$ & 0.011 \\
\hline $\mathrm{X}_{s}(\Omega)$ & & $\operatorname{Im}\left(\underline{Z}_{s}^{s}\right)$ & 2.223 \\
\hline $\mathrm{L}_{s}$ (Henry) & & $\mathrm{x}_{s} / \omega_{0}$ & 0.0070 \\
\hline M (Henry) & 0.139 & & \\
\hline$\left(\mathrm{k}^{2}\right)^{b}$ & 0.9 & & \\
\hline $\mathrm{L}_{r}$ (Henry) & & $3 \mathrm{M}^{2} /\left(k^{2} L_{s}\right)$ & 9.10 \\
\hline$\widehat{\mathrm{I}}_{\mathrm{exc}}(\mathrm{A})$ & & $\left|\underline{\mathrm{E}}_{0}\right| /\left(M \omega_{0}\right)$ & 1009 \\
\hline \multicolumn{4}{|l|}{ T\&D } \\
\hline$\underline{\mathrm{Z}}_{\varphi}(\Omega)$ & cf. below & & \\
\hline$\overline{\mathrm{R}}_{\varphi}^{\varphi}(\Omega)$ & 0.405 & & \\
\hline $\mathrm{X}_{\varphi}(\Omega)$ & 0.512 & & \\
\hline $\mathrm{L}_{\varphi}$ (Henry) & 0.0016 & & \\
\hline \multicolumn{4}{|l|}{ Consumption } \\
\hline $\mathrm{R}_{0}(\Omega)$ & & $f(\mathrm{P}$, all $\underline{\mathrm{Z}})$ & 3.50 \\
\hline
\end{tabular}

$a_{f()}$ means: function of the variables inside the brackets.

$b^{b} k$ is the coupling coefficient between rotor and stator.

Table 1: Parameters on which the dynamic analysis of a power system's response to a load fluctuation relies.

\begin{tabular}{llc}
\hline Voltages (kV) & $\left|\underline{\mathrm{E}}_{0}\right|$ & 44.1 \\
& $\left|\underline{\mathrm{U}}_{0}\right|$ & 36.4 \\
& $\left|\underline{\mathrm{U}}_{\text {load }, 0}\right|$ & 32.3 \\
\hline Currents (A) & $\left|\underline{\mathrm{I}}_{0}\right|$ & 9216 \\
& $\widehat{\mathrm{I}}_{\text {exc }}$ & 1009 \\
\hline Powers (MW) & $\mathrm{P}_{\text {mech-ext }}$ & 1000 \\
& $\mathrm{P}_{\text {elec-ext, }}$ & 894 \\
& $\mathrm{P}_{\text {Joule }, 0}$ & 106 \\
\hline Power angle & $\delta$ & $27.4^{\circ}$ \\
\hline Reserves (MJ) & $\mathrm{F}$ & 3.5 \\
& $\mathrm{E}_{\text {kin }}$ & 706 \\
\hline Time constants & $\tau_{\text {elec }}(\mathrm{ms})$ & 2.2 \\
& $\tau_{\text {mech }}(\mathrm{s})$ & 7.06 \\
\hline
\end{tabular}

Table 2: Values in the one-loop circuit before a fluctuation for a power system with $\mathrm{P}_{\text {mech-ext }}=1000 \mathrm{MW}, \mathrm{H}_{\text {kin }}=3 \mathrm{~s}$, and $\mathrm{H}_{\text {mag }}=3 \mathrm{~ms}$.

current only change with $\omega(t)$. A series of curves, for $\mathrm{H}_{\text {kin }}$ varying between 3 and $25 \mathrm{~s}$, shows that the frequency deviation decreases with greater values of $\mathrm{H}_{\text {kin }}$ and demonstrates the role of $\mathrm{H}_{\text {kin }}$ in improving system reliability. Further analyses also show that the frequency drop increases with $\mathrm{H}_{\text {mag }}$, thus reinforcing the need for high values of $\mathrm{H}_{\text {kin }}$. 


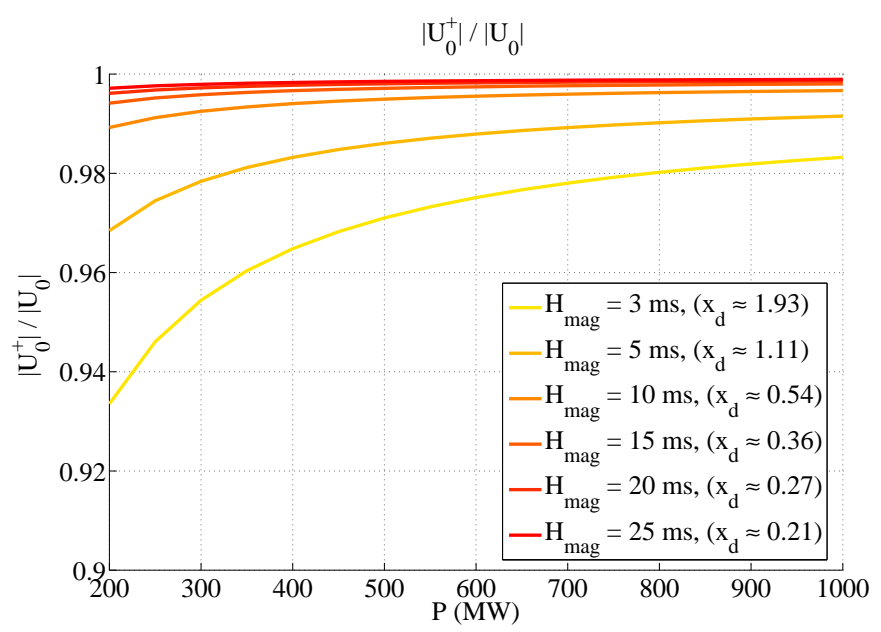

(a) Terminal voltage $\left|\mathrm{U}_{0}^{+}\right|$after the fluctuation which is independent of $\mathrm{H}_{\text {kin }}$.

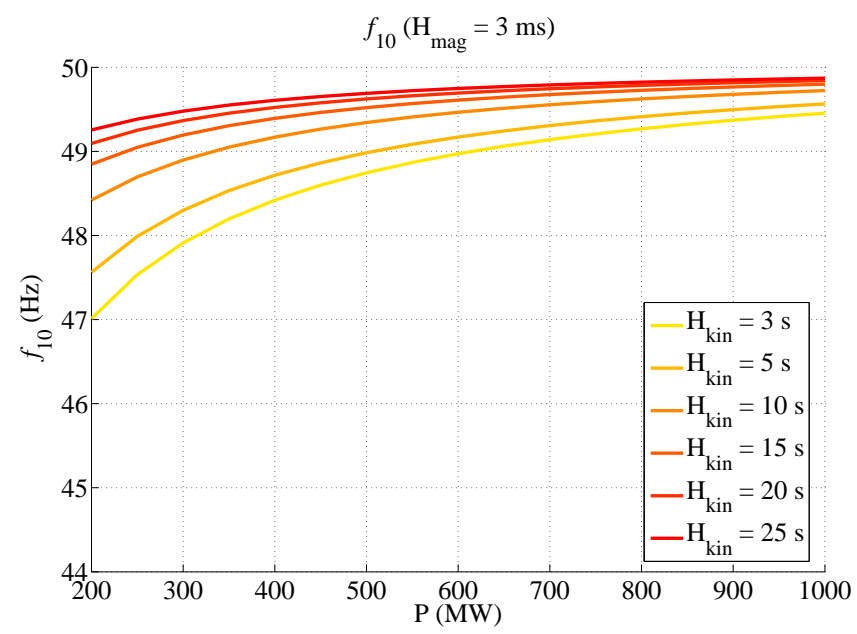

(b) Frequency drop $f_{10} 10$ seconds after the fluctuation for $\mathrm{H}_{\mathrm{mag}}=3 \mathrm{~ms}$.

Figure 3: Voltage and frequency deviations in the one-loop circuit after a load fluctuation where $\Delta \mathrm{P}=52 \mathrm{MW}$.

Furthermore, both figures show that a fixed load fluctuation has a stronger impact on power systems with low generation capacities. For instance, when $\mathrm{P}_{\text {mech-ext }}=200 \mathrm{MW},|\mathrm{U}|$ may drop to 0.94 of its initial value and $f_{10}$ to $47 \mathrm{~Hz}$, thereby illustrating the intrinsic weakness of small power systems. 


\section{Assessing the Reliability of Power Supply}

In this section, we quantify the impacts of the share of renewable energy sources on the power supply reliability in the future. Such results are critical to assess the technical feasibility of a given power mix and to evaluate the equivalent needed magnetic and kinetic energy reserves to be provided to compensate the loss resulting with the new types of power generation.

The reliability indicators are combined to a long-term analysis of the power system in Reunion Island which aims at a production mix with $100 \%$ of renewable energy sources by 2030 [50]. Considering that the current level of renewable energies in electricity production is only $36 \%$ and that existing power plants are due to be decommissioned within the next two decades [51], the electricity sector will need to change substantially to reach this ambitious target. However, such a change may highly weaken the reliability of supply since the power system on Reunion is small, remote and weakly meshed. The analysis is performed with the long-term energy planning model TIMESReunion which evaluates the power sector investments options and activity levels against a multiplicity of load growth and resource supply scenarios.

\subsection{TIMES-Reunion model}

TIMES-Reunion is a bottom-up optimization model of the MARKAL / TIMES family of energy models, developed under the auspices of the International Energy Agency since the mid-1980s [52, 53]. In TIMES models, the energy sector is described as a chain of transformations between the primary energy resources and the final energy demand. The transformations are explicit input/output relationships between individual technologies and commodity flows they produced or consumed. Such a detailed approach provides a complete description of the substitution possibilities among the available technologies from primary resources to final energy services. Hence, the principle of TIMES models is to maximize the total surplus of the energy system over a large time horizon (typically several decades) in an intertemporal optimization framework. As a result, the solution provides the levels of energy resources and technologies that are effectively used from the total available set of possibilities modeled, and is therefore well suited for a detailed investigation of future technology choices. For power sectors' description, flow equilibrium conditions are published separately for several timeslices to follow the load curve and distinguish between the different hours of a day. In TIMES-Reunion model, one year is divided into two seasons (summer and 
sugar season), and one day into eight timeslices, each representing a few hours of a day. A peak reserve constraint also guarantees the setting-up of an additional capacity reserve and stipulates that the total production capacity must be oversized by a given percentage to satisfy the peak demand and insure against grid contingencies. The TIMES-Reunion model was specifically developed to describe Reunion Island's electricity sector and study its responses to contrasted scenarii for the period 2008-2030 [54, 34]. Two scenarii investigate possible assumptions for the long-term development of the electricity sector [34]:

- a baseline scenario, named BASE, is defined for comparison purposes. The current production mix is simply extended over the time horizon: no limit is set on fossil fuel imports and no specific incentives promote the use of renewable energy sources;

- a "renewable" scenario, called PV-OCE, inversely tends towards energy autonomy on Reunion Island by 2030 and promotes a broad range of renewable energy sources with ambitious targets for the development of photovoltaics (700 MW) and ocean energy (150 MW).

In the baseline scenario, the shares of electricity production remains stable over the time horizon, namely over a year two thirds of electricity production relies on coal combustion; sugarcane bagasse increases in electricity production as expected with the greater available potential in 2030; photovoltaics, ocean and wind energies show no sign of improvement. Inversely, in the PV-OCE scenario, the shares of renewable sources steadily increase to meet the target in 2030, i.e. coal combustion progressively declines along with fuel oil combustion while sugarcane bagasse and wood combustion keep on growing; hydropower remains stable over the time horizon; most importandly photovoltaics and ocean energies sharply rise due to high levels of installed capacities. Intermittent energy sources represent a fifth of the annual electricity production in 2030 in the scenario PV-OCE.

The most significant impact of intermittent sources is illustrated by the figure 4 which depicts the daily production for an average day in the summer of 2030. Such a result is a standard output of TIMES models. The figure shows that in the PV-OCE scenario, electricity production relies on renewable energy sources during all day: solar production, limited to 10 hours by day, rises abruptly during the sunny hours and represent almost two thirds of electricity production during sunny hours (7 to 17); production from biomass 


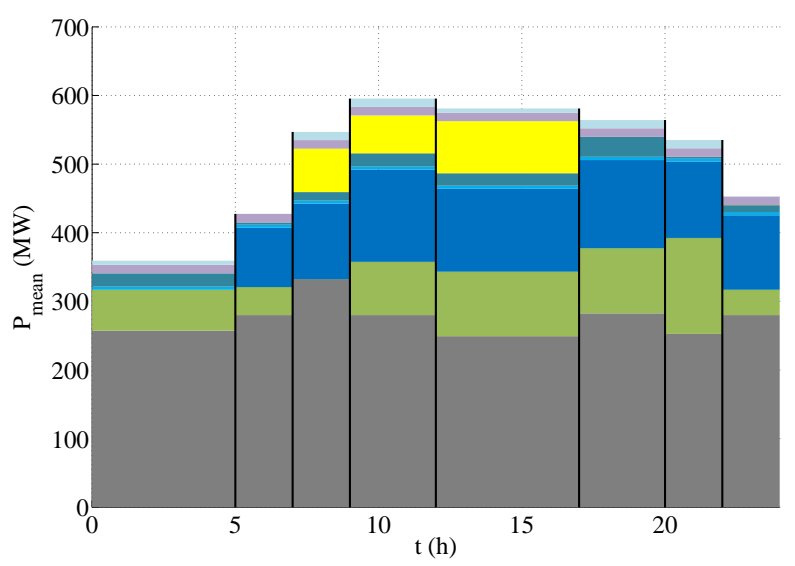

(a) Baseline scenario.

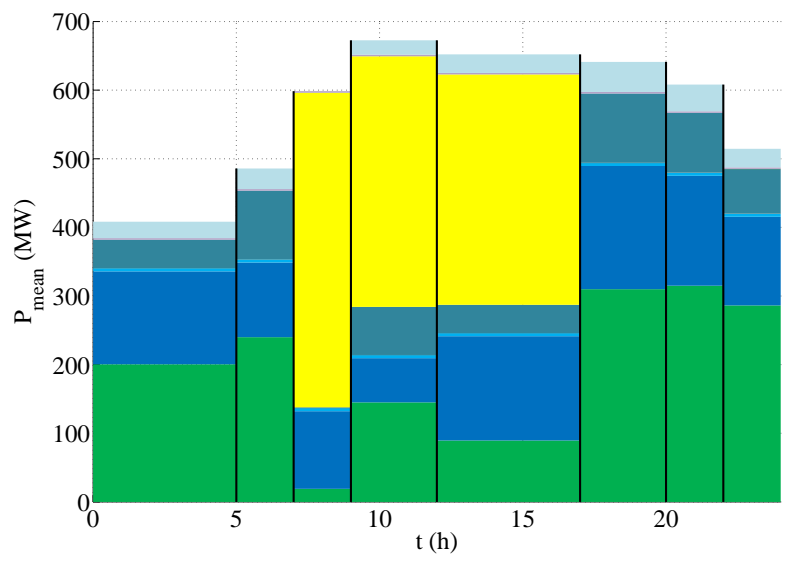

(b) Renewable scenario (PV-OCE).

$\begin{array}{lll}\text { Coal } & \text { Coal/sugarcane } & \text { Heavy fuel oil } \\ \square \text { Distillate fuel oil } & \text { Sugarcane / wood } & \text { Hydropower (dams) } \\ \square \text { Hydropower (run of river) } & \text { Biogaz } & \text { Photovoltaïcs } \\ \square \text { Wind energy (onshore) } & \text { OTEC } & \text { Wave energy }\end{array}$

Figure 4: Daily production in the summer 2030 in the two scenario. In the renewable scenario (PV-OCE), photovoltaics represent nearly two thirds of the production during the day (between 7 am and $5 \mathrm{pm}$ ).

(cane and wood), hydropower, ocean and wind energy remains almost stable. Inversely, in the baseline scenario, coal combustion represents more than two thirds of electricity production in 2030 while hydropower production contribute to a quarter of electricity production. Electricity production from 
other renewable sources is hardly noticeable.

Further analyses for a winter day in 2030, conducted in [34], depict less different daily production mixes for the two scenarii. The production from sugarcane bagasse and wood combustion in winter represent two thirds of electricity production in PV-OCE. Indeed the sugarcane bagasse is a coproduct of the sugar factories localized next to power plants that is available only during winter which is the sugar production period. Consequently, the shares of solar and ocean energy is lower during winter and correspond at most to one fifth of eletricity production. In the baseline scenario, the daily production is almost the same as in the figure 4, but with a higher production from sugarcane bagasse combustion.

\subsection{Reliability Indicators' Long-Term Evolution}

In the following calculations, related to the previous long-term scenarii, the indicators defined in section 3 are used to quantify reliability of supply with increasing shares of intermittent sources. The figure 5 presents the evolutions of $\mathrm{H}_{\text {mag }}$ and $\mathrm{H}_{\text {kin }}$, based on technical data [55], and provides a precise evaluation of the available reserves on the system for the timeslice from 9am to 12 am until 2030 in summer (dashed lines with diamond or square according to the scenario) and in winter (solid lines with triangle or circle).

The most important difference between the baseline and the PV-OCE scenarii occur during summer (dashed lines) where the contribution of intermittent sources (mostly photovoltaics) reaches the higher share in the daily production. The indicators start to decrease from 2020 in the PV-OCE scenario with the sharp rise of photovoltaics in the production mix. Inversely they remain constant in the baseline scenario which presents few intermittent sources. Indeed, as photovoltaics and wind power mostly supply electricity through electronic power converters, they barely participate in magnetic and kinetic reserves. Therefore, with growing shares of intermittent sources in electricity production, $\mathrm{H}_{\text {mag }}$ and $\mathrm{H}_{\text {kin }}$ abruptly decrease, thus illustrating that intermittent sources are detrimental to the reliability of power supply if no extra-equipment is planned to increase the dynamic reserves $\mathrm{F}$ and $\mathrm{E}_{\text {kin }}$.

The drop in the indicators' assessment between the two scenarios is smaller during winter (solid lines). In fact, winter is also the period during which sugarcane bagasse can produce electricity: sugarcane bagasse and wood power plants contribute to at least two thirds of the production in the winter 2030 in the PV-OCE scenario [54]. Since sugarcane bagasse and 


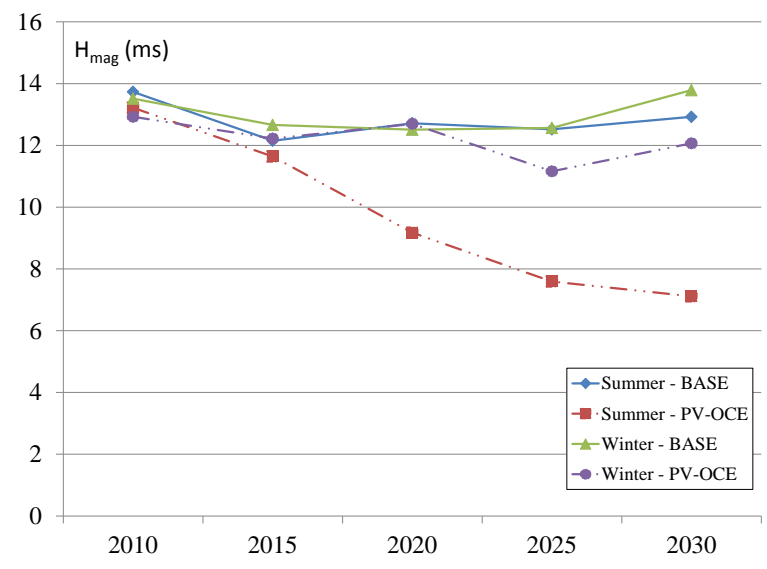

(a) $\mathrm{H}_{\mathrm{mag}}(\mathrm{ms})$.

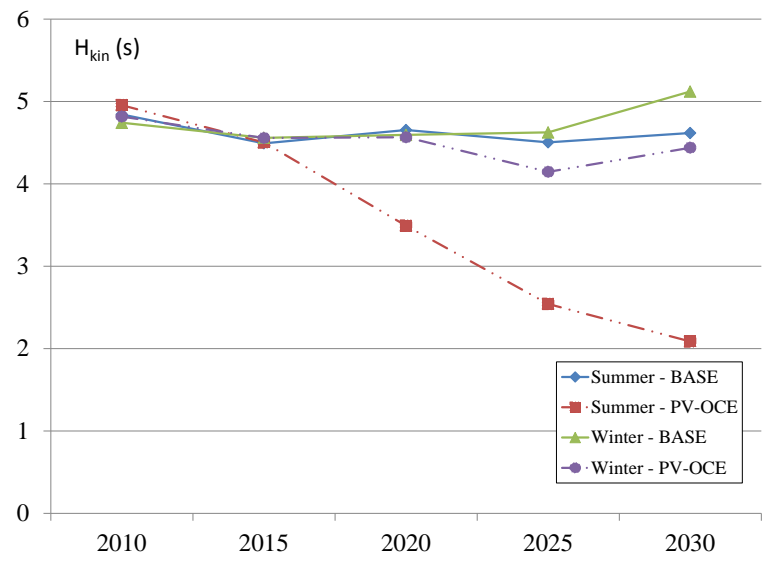

(b) $\mathrm{H}_{\text {kin }}(\mathrm{s})$.

Figure 5: Reliability indicators in the Reunion Island during 9 am to 12 am until 2030 for a scenario with $100 \%$ renewable energy sources in electricity production, PV-OCE (dashed lines), compared to a business as usual one, BASE (solid lines). The two subfigures depict the reliability indicators for a summer day (diamond, square) and a winter day (triangle, circle) for the two scenarios.

wood power plants functioning in the PV-OCE scenario have similar technical characteristics than the coal power plants used in the baseline scenario, it explains that the indicators have similar values during winter. Consequently the calculations of $\mathrm{H}_{\text {mag }}$ and $\mathrm{H}_{\text {kin }}$ lead to close values.

In the figure 5 the indicators follow similar variations, since production capacities currently participate almost identically in the two reserves. Thereby, 
any change in the production mix leads to similar effects on $\mathrm{H}_{\text {mag }}$ and $\mathrm{H}_{\text {kin }}$. However, $\mathrm{H}_{\text {mag }}$ and $\mathrm{H}_{\text {kin }}$ will evolve differently if specific technologies, among which storage units develop: in such a case, $\mathrm{H}_{\text {kin }}$ is expected to increase while $\mathrm{H}_{\text {mag }}$ could remain unchanged. It would therefore be interesting to follow the evolution of the indicators in the case where storage units are used to mitigate the impact of photovoltaics on the reliability of power supply. Dealing more generally with intermittent sources (mostly wind power and photovoltaics), one of the solutions being proposed to improve the performance of renewable sources is indeed to integrate energy storage devices, such as pumped storage hydro plants, hydrogen storage, flywheels, electrochemical batteries, superconducting magnetic energy storage, into the power system. Recent works have thus analyzed the impacts of energy storage devices on power system operation $[56,57,58,59]$. These papers show that energy storage systems can secure reliability of supply and reduce the instability phenomena. Their impacts on reliability of supply and subsequent overcosts should also be investigated in a long-term perspective.

\subsection{Real-Time Management}

To limit the development of intermittent sources in its overseas territories, the French government followed the recommendation of the local system operator, EDF, and set a legal limit of $30 \%$ on the level of instantaneous production of intermittent sources in electricity production in 2008. In TIMESReunion, it is possible to analyze the impacts of the $30 \%$ management rule on the daily variations of the indicator. Load curves for the two seasons are built thanks to the aforementioned timeslices, and the daily variations of the $\mathrm{H}_{\text {mag }}$ and $\mathrm{H}_{\text {kin }}$ are based on the daily production mixes given by TIMESReunion. Figure 6 presents the daily curves of $\mathrm{H}_{\text {mag }}$ and $\mathrm{H}_{\text {kin }}$ during summer 2030. The baseline scenario and the scenario PV-OCE are now compared to another scenario, entitled 30\%, deduced from PV-OCE but enforcing the $30 \%$ management rule of intermittent sources. In the scenario PV-OCE, denoted by dashed lines, both indicators strongly fluctuate within a day:

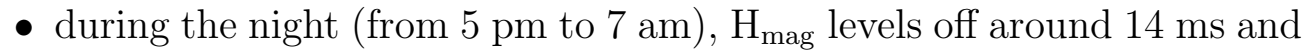
$\mathrm{H}_{\text {kin }}$ around $4.5 \mathrm{~s}$. During these hours, electricity is mostly produced by non-intermittent units which participate efficiently in the levels of reserves;

- during daytime, when high levels of photovoltaic production meet approximately two thirds of the electricity demand, indicators are halved, 


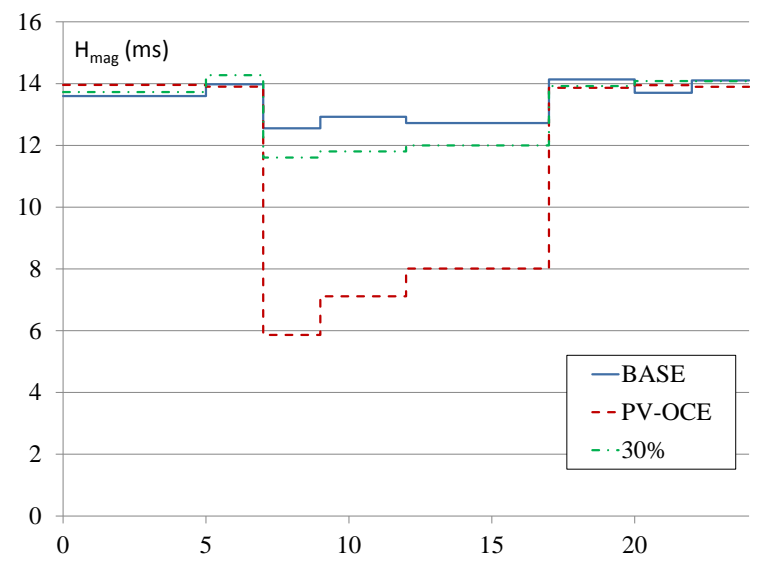

(a) $\mathrm{H}_{\text {mag }}(\mathrm{ms})$.

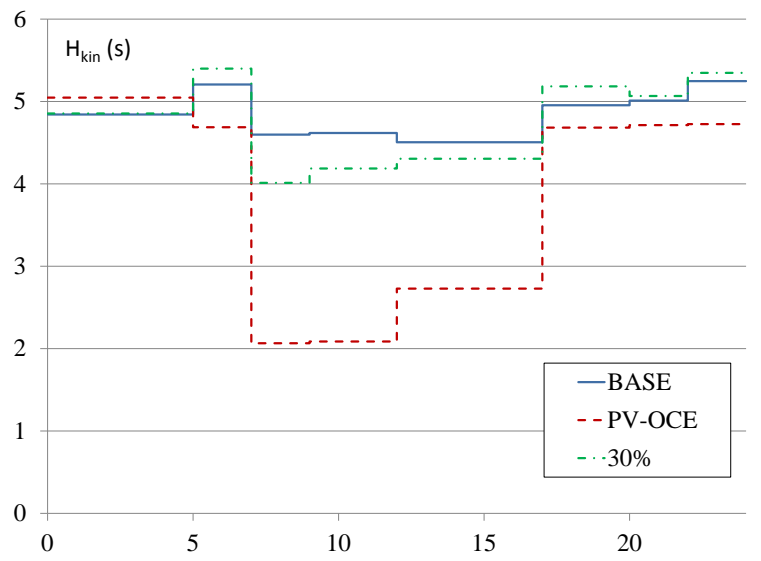

(b) $\mathrm{H}_{\text {kin }}(\mathrm{s})$.

Figure 6: Daily variations of $\mathrm{H}_{\mathrm{mag}}$ and $\mathrm{H}_{\text {kin }}$ in the summer 2030 in the Reunion Island. The figures present the impact of the $30 \%$ limitation of intermittent sources on the reliability of supply in the scenario 30\% (mixed lines) compared to the scenarii PV-OCE (dashed lines) and BASE (solid lines).

thereby pointing to weaker reliability of supply.

Inversely, in the $30 \%$ scenario, denoted by the mixed lines, $\mathrm{H}_{\text {mag }}$ levels off at around $12 \mathrm{~ms}$ and $\mathrm{H}_{\mathrm{kin}}$ around $4 \mathrm{~s}$, showing that the reserves are twice as high during daytime, i.e. the most critical hours, with the $30 \%$ management rule. Enforcing a real-time limit on the share of intermittent sources can consequently restore reliability of power supply, almost to the same levels 
as in the baseline scenario. Such result validates the $30 \%$ rule fixed by the regulator to limit the spread of intermittent sources to an appropriate extent.

Moreover, the previous example illustrates the key role the indicators can play in improving the real-time management of reliability of supply. Indicators can be used to control levels of reserves in a power system, thus restoring the reliability of power supply in real-time. This approach is protected by the patent [60] which describes a method based on the magnetic and kinetic reserves for estimating the stability of a power system. The patent indicates how to manage a power system by assessing at least one parameter of stability based on the magnetic and / or kinetic reserves it stores. Such a method provides a critical and necessary condition for ensuring a reliable power supply, which might not be sufficient since it does not address the spatial characteristics of power systems' reliability.

\section{Conclusion}

The developments presented in this paper were described in a $\mathrm{PhD}$ thesis defended in 2011 that the authors want to make available to the international community [54]. Since then, research on this topic has been carried out and a recent publication illustrates how the approach developed herein can be useful to determine the level of intermittency compatible with reliability requirements [61].

The reliability indicators $H_{\text {mag }}$ and $H_{\text {kin }}$ presented in this paper provide valuable indications to debate the most appropriate conditions for ensuring the reliability of supply. They make it possible to address reliability issues for problems involving different timescales, namely by analyzing the long-term evolution of reliability in planning exercises, or by enhancing power system management through the real-time control of magnetic and kinetic reserves. Whatever the timescale considered, indicators are crucial for debating the technical feasibility of power mixes that include high shares of intermittent sources, since they may alter the reliability of supply if the issue is not addressed properly. They consequently make it possible to choose between increasing shares of intermittent sources and maintaining reliability of power supply. Besides, to consider the forthcoming changes of the power sector, storage technologies must complete our analysis, together with changes in consumption patterns induced with the development of demand response. 


\section{Acknowledgment}

The authors would like to thank the Chair Modeling for sustainable development, driven by Mines ParisTech, École des Ponts ParisTech, AgroParisTech and ParisTech; and supported by ADEME, EDF, RENAULT, SCHNEIDER ELECTRIC and TOTAL, that has supported this work. They also would like to address their hearty thanks to Edi Assoumou and Jean-Paul Marmorat from Mines ParisTech (France, Sophia-Antipolis), for their stimulating comments and constant interest in this work; and to Michel Barrault, former Head Scientist at Schneider Electric (France, Grenoble), for very helpful discussions.

\section{Appendix A. Magnetic energy $F$ in the one-loop circuit}

This appendix ims at determining the magnitudes of the magnetic reserve $\mathrm{F}$ and describes the calculations leading to an explicit formulation of $\mathrm{F}$ for the one-loop circuit depicted in the figure 2 . The phasor representation provided in figure A.7 illustrates the relations of voltages and currents in the one-loop circuit.

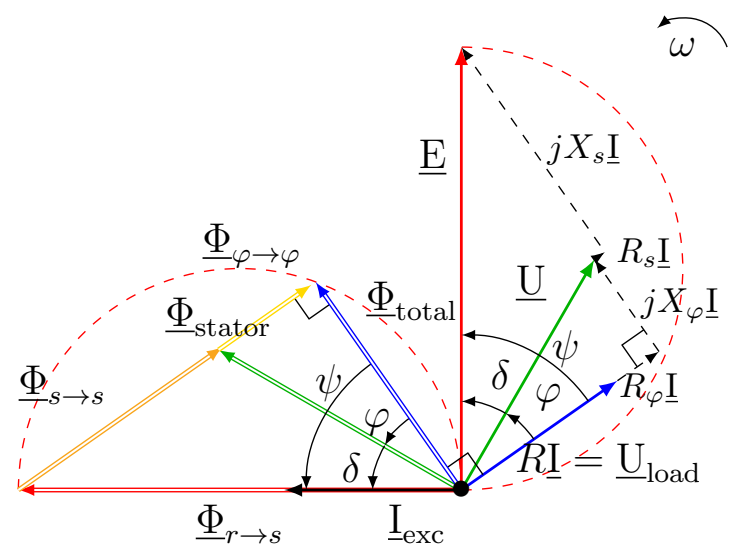

Figure A.7: Phasor representation of voltages and currents in the one-loop circuit. Singleline arrows represent voltages and currents, while double-line arrows stand for the flux density associated with the latter.

Underlined uppercase characters denote the complex number that contains the amplitude and phase angle of a sinusoidal function, and starred characters denote their complex conjugate. 
Assuming linear electromagnetic behavior laws, general formulations for $\mathrm{G}$ and $\mathrm{F}$ read:

$$
\begin{aligned}
& \mathrm{G}=-\frac{1}{2} \operatorname{Re}\left(\underline{\Phi}_{\mathrm{I}_{\text {exc }}^{*}}^{*}\right) \\
& \mathrm{F}=\mathrm{G}+\operatorname{Re}\left(\underline{\Phi}_{\text {exc }}^{*}\right)=\frac{1}{2} \operatorname{Re}\left(\underline{\Phi}_{\underline{I}_{\text {exc }}^{*}}\right)
\end{aligned}
$$

where $\underline{\Phi}$ is the flux density, and $\underline{I}_{\text {exc }}$ is the fictive sinusoidal current representing the rotating dc excitation current $\mathrm{I}_{\text {exc }}$.

Focusing on the production side, the magnetic energy $\mathrm{F}\left(\mathcal{V}_{\text {prod }}\right)$ is the sum of the following terms:

- the rotor $(r)$ self and mutual inductances:

$$
\mathrm{F}_{\text {rotor }}=\frac{1}{2} \operatorname{Re}\left(\underline{\Phi}_{r \rightarrow r} \underline{\mathrm{I}}_{\text {exc }}^{*}\right)
$$

where $\underline{\Phi}_{x \rightarrow y}$ describes the magnetic flux induced by the coil winding $x$ in the coil winding $y$.

- the stator $(s)$ self and mutual inductances (I is the current exciting the flux density in the stator coil windings):

$$
\mathrm{F}_{\text {stator }}=\frac{3}{2} \operatorname{Re}\left(\underline{\Phi}_{s \rightarrow s} \underline{I}^{*}\right)
$$

- the stator-rotor mutual inductances:

$$
\mathrm{F}_{\text {linkage }}=\frac{3}{2} \operatorname{Re}\left(\underline{\Phi}_{s \rightarrow r} \underline{I}_{\text {exc }}^{*}+\underline{\Phi}_{r \rightarrow s} I^{*}\right)
$$

For transport and distribution, the mutual inductances between lines or transformers' coil windings induce:

$$
\mathrm{F}\left(\mathcal{V}_{\mathrm{T \& D}}\right)=\frac{3}{2} \operatorname{Re}\left(\underline{\Phi}_{\varphi \rightarrow \varphi} \underline{I}^{*}\right)
$$

Ignoring the mutual inductances between $\mathcal{V}_{\text {prod }}$ and $\mathcal{V}_{\text {T\&D }}$, an explicit formulation of the total magnetic energy is provided by adding the expressions (A.3), (A.4), (A.5) and (A.6):

$$
\mathrm{F}=\frac{1}{2} \mathrm{~L}_{r}\left|\underline{\mathrm{I}}_{\text {exc }}\right|^{2}\left(1-\frac{3 \mathrm{M}^{2}}{\mathrm{~L}_{r}\left(\mathrm{~L}_{s}+\mathrm{L}_{\varphi}\right)} \sin ^{2} \psi\right)
$$

where: 
- $\mathrm{L}_{r}$ represents the rotor self and mutual inductances;

- $\mathrm{M}$ is the value of the stator-rotor mutual inductances;

- |.| denotes the absolute value of a complex number;

- $\psi=(\delta+\varphi)$ is the phase difference between the open-circuit voltage $\underline{\mathrm{E}}$ and the current $\underline{\mathrm{I}}$.

According to (15), $\mathrm{F}$ depends on the properties of the production side $\left(\mathrm{L}_{r}, \mathrm{~L}_{s}, \mathrm{M}\right)$, and on the transport and distribution equipment $\left(\mathrm{L}_{\varphi}\right)$. The magnetic energy also varies with the load state of the system, since $\left|\underline{I}_{\text {exc }}\right|$ and $\psi$ change with the power delivered to $\mathrm{R}$.

\section{References}

[1] International Energy Agency (Organisation for Economic Cooperation and Development)). Energy Technology Perspectives : scenarios and strategies to 2050. International Energy Agency (Organisation for Economic Cooperation and Development); 2008.

[2] Ilic MD. From hierarchical to open access electric power systems. Proceedings of the IEEE 2007;95(5):1060-84.

[3] Golusin M, Ivanovic OM, Redzepagic S. Transition from traditional to sustainable energy development in the region of western balkans current level and requirements. Applied Energy 2013;101(0):182 -91.

[4] Holttinen H, Meibom P, Orths A, Lange B, O'Malley M, Tande JO, et al. Impacts of large amounts of wind power on design and operation of power systems, results of iea collaboration. In: Proc. $8^{\text {th }}$ International Workshop on Large-Scale Integration of Wind Power into Power Systems as well as on Transmission Networks of Offshore Wind Farms. Bremen, Germany; 2009,.

[5] Esteban M, Leary D. Current developments and future prospects of offshore wind and ocean energy. Applied Energy 2012;90(1):128 -36. Energy Solutions for a Sustainable World, Special Issue of International Conference of Applied Energy, ICA2010, April 21-23, 2010, Singapore. 
[6] Haller M, Ludig S, Bauer N. Bridging the scales: A conceptual model for coordinated expansion of renewable power generation, transmission and storage. Renewable and Sustainable Energy Reviews 2012;16(5):2687 -95 .

[7] Lund H, Mathiesen B. Energy system analysis of $100 \%$ renewable energy systems: The case of Denmark in years 2030 and 2050. Energy 2009;34(5):524 -31.

[8] Krajacic G, Duic N, da Graca Carvalho M. How to achieve a 100\% RES electricity supply for Portugal? Applied Energy 2011;88(2):508 -17.

[9] Segurado R, Krajacic G, Duic N, Alves L. Increasing the penetration of renewable energy resources in s. vicente, cape verde. Applied Energy 2011;88(2):466 -72. The 5th Dubrovnik Conference on Sustainable Development of Energy, Water and Environment Systems, held in Dubrovnik September/October 2009.

[10] Pina A, Silva CA, Ferrao P. High-resolution modeling framework for planning electricity systems with high penetration of renewables. Applied Energy 2013;112(0):215 -23.

[11] Trutnevyte E. EXPANSE methodology for evaluating the economic potential of renewable energy from an energy mix perspective. Applied Energy 2013;111(0):593 - 601.

[12] Purvins A, Zubaryeva A, Llorente M, Tzimas E, Mercier A. Challenges and options for a large wind power uptake by the european electricity system. Applied Energy 2011;88(5):1461 -9. doi: 10.1016/j.apenergy.2010.12.01.

[13] Orioli A, Gangi AD. Load mismatch of grid-connected photovoltaic systems: Review of the effects and analysis in an urban context. Renewable and Sustainable Energy Reviews 2013;21(0):13 - 28.

[14] Beccali M, Brunone S, Finocchiaro P, Galletto J. Method for size optimisation of large windhydrogen systems with high penetration on power grids. Applied Energy 2013;102(0):534 -44. Special Issue on Advances in sustainable biofuel production and use - XIX International Symposium on Alcohol Fuels - ISAF. 
[15] Lin SY, Chen JF. Distributed optimal power flow for smart grid transmission system with renewable energy sources. Energy 2013;56(0):184 -92 .

[16] Moura PS, de Almeida AT. The role of demand-side management in the grid integration of wind power. Applied Energy 2010;87(8):2581 -8.

[17] Siddiqui O. The green grid: Energy savings and carbon emissions reductions enabled by a smart grid. Tech. Rep. 1016905; Electrical Power Research Institute; Palo Alto, CA; 2008.

[18] Joung M, Kim J. Assessing demand response and smart metering impacts on long-term electricity market prices and system reliability. Applied Energy 2013;101(0):441 -8.

[19] Sun T, Wang X, Ma X. Relationship between the economic cost and the reliability of the electric power supply system in city: A case in shanghai of china. Applied Energy 2009;86(10):2262 -7.

[20] Chaiamarit K, Nuchprayoon S. Modeling of renewable energy resources for generation reliability evaluation. Renewable and Sustainable Energy Reviews 2013;26(0):34 - 41 .

[21] European Network of Transmission System Operators for Electricity. Operation Handbook. Tech. Rep.; European Network of Transmission System Operators for Electricity; 2004.

[22] Bergen AR, Vittal V. Power System Analysis. Prentice-Hall Series; 2 ed.; 2000.

[23] Momoh JA, El-Hawary M, Adapa R. A review of selected optimal power flow literature to 1993. part I \& II. IEEE Transactions on Power Systems 1999;14(1):96 - 111 .

[24] Varadarajan M, Swarup K. Network loss minimization with voltage security using differential evolution. Electric Power Systems Research $2008 ; 78(5): 815-23$.

[25] Billinton R, Allan R. Reliability evaluation of power systems. Springer; 1996. 
[26] Endrenyi J, Anders G, Leite da Silva A. Probabilistic evaluation of the effect of maintenance on reliability. An application to power systems. IEEE Transactions on Power Systems 1998;13(2):576 -83.

[27] Bilan Prévisionnel de l'équilibre offre-demande d'électricité en France. Tech. Rep.; Réseau de Transport d'Électricité; 2011.

[28] Kagiannas AG, Askounis DT, Psarras J. Power generation planning: a survey from monopoly to competition. International Journal of Electrical Power \& Energy Systems 2004;26(6):413 -21.

[29] Furusawa K, Okada K, Asano H. A method of evaluating transmission network expansion plan considering security constraints and supply reliability index. In: IEEE/PES Power Systems Conference and Exposition PES '09. 2009, p. 1-6.

[30] Landau LD, Lifshitz EM. Mechanics; vol. 1. Pergamon Press, Oxford; 1960.

[31] Sauer PW, Pai MA. Power system dynamics and stability. Prentice-Hall New Jersey; 1998.

[32] Pai MA. Energy function analysis for power system stability. Springer; 1989.

[33] Mazauric VG. From thermostatistics to Maxwell's equations: a variational approach of electromagnetism. IEEE Transactions on Magnetics 2004;40:945-8.

[34] Drouineau M. Modélisation prospective et analyse spatio-temporelle : intégration de la dynamique du réseau électrique. Ph.D. thesis; MINES ParisTech; 2011.

[35] Landau LD, Lifshitz EM. Electrodynamics of continuous medium. Pergamon Press, Oxford; 1960.

[36] Christen T. Application of the maximum entropy production principles to electrical system. Journal of Physics D: Applied Physics 2006;39(20):4497 -503. 
[37] Mazauric V, Maïzi N. A global approach of electromagnetism dedicated to further long-term planning. vol. 7. WILEY-VCH Verlag; 2007, p. 2130003-. doi:10.1002/pamm.200700210.

[38] Mazauric V, Maïzi N. Optimality principles for the sustainability of electrical systems: a thermodynamic approach. In: International Conference and Applied Energy. A10806; PR China, Suzhou; 2012,.

[39] Hammond P. Energy methods in electromagnetism. Monographs in electrical and electronic engineering. Oxford: Clarendon Press; 1981.

[40] Eco-design stakes of electrical steel: Dynamic losses sensitivity. Journal of Magnetism and Magnetic Materials 2008;320(20):e1070 -3. Proceedings of the 18th International Symposium on Soft Magnetic Materials.

[41] Ladas D, Mazauric V, Meunier G, Chadebec O, Ebene-Ebene M, Marechal Y, et al. An energy based approach of electromagnetism applied to adaptive meshing and error criteria. Magnetics, IEEE Transactions on $2008 ; 44(6): 1246-9$.

[42] Rondot L, Mazauric V, Wendling P. An energy-compliant magnetodynamic error criterion for eddy-current calculations. Magnetics, IEEE Transactions on 2010;46(6):2353 -6. doi:10.1109/TMAG.2010.2041054.

[43] Chatelain J. Machines électriques, Tomes 1 et 2; vol. X of Traité d'Électricité. Presses Polytechniques et Universitaires Romandes; 1984.

[44] Drouineau M, Mazauric V, Assoumou E, Maïzi N. Network reliability assessment towards long term planning. In: Energy 2030 Conference, 2008. ENERGY 2008. IEEE. 2008, p. $1-5$. doi: 10.1109/ENERGY.2008.4781024.

[45] Stevenson WD. Elements of power system analysis, Fourth Edition. McGraw-Hill in Electrical Engineering; 1982.

[46] Mémento de la sûreté du système électrique. Tech. Rep.; Réseau de Transport d'Électricité; 2004.

[47] Hirst E, Kirby B. Electric-power ancillary services. Tech. Rep. ORNL/CON-426; Oak Ridge National Laboratory; Oak Ridge, Tennessee; 1996. 
[48] Raineri R, Ríos S, Schiele D. Technical and economic aspects of ancillary services markets in the electric power industry: an international comparison. Energy Policy 2006;34:1540 -55.

[49] Einstein TH. Magnetic energy storage in synchronous machines. IEEE Transactions on Power Apparatus and Systems 1973;92(1):346-51.

[50] Agence Régionale de l'Énergie Réunion. Tech. Rep.; Agence Régionale de l'Énergie Réunion; 2009.

[51] Bilan Prévisionnel Pluriannuel : investissements en production (La Réunion). Tech. Rep.; EDF (Électricité de France); 2011.

[52] Loulou R, Goldstein G, Noble K. Documentation of the MARKAL Family of Models. Energy Technology Systems Analysis Program; 2004.

[53] Loulou R, Remme U, Kanudia A, Lehtila A, Goldstein G. Documentation for the TIMES Model (Parts I to III). Energy Technology Systems Analysis Program; 2005.

[54] Drouineau M, Maïzi N, Assoumou E, Mazauric V. A TIMES model of the Reunion Island for analysing the reliability of electricity supply. In: International Energy Workshop. 2011,.

[55] Anderson PM, Fouad AAA. Power system control and stability. The Iowa State University Press; 1977.

[56] Divya K, Ostergaard J. Battery energy storage technology for power systemsan overview. Electric Power Systems Research 2009;79(4):511 -20 .

[57] Koh L, Yong GZ, Peng W, Tseng K. Impact of energy storage and variability of $\{\mathrm{PV}\}$ on power system reliability. Energy Procedia 2013;33(0):302 -10. PV Asia Pacific Conference 2012.

[58] Yuan Y, Zhang X, Ju P, Qian K, Fu Z. Applications of battery energy storage system for wind power dispatchability purpose. Electric Power Systems Research 2012;93(0):54 - 60 .

[59] Hasan NS, Hassan MY, Majid MS, Rahman HA. Review of storage schemes for wind energy systems. Renewable and Sustainable Energy Reviews 2013;21(0):237 -47. 
[60] Maïzi N, Drouineau M, Mazauric V, Bouckaert S. Patent FR 1161087 / WO2013 079700: Procédé d'estimation de la fiabilité d'un système électrique. 2012.

[61] Mazauric V, Bouckaert S, Drouineau M, Maïzi N. How much intermittency in the power mix: an energy-based approach. In: International Conference on Applied Energy. 2013,. 